\title{
Lack of Environmental Sustainability in Youth Training at Higher Education
}

\author{
*Syed Kaleem Ullah Shah Bukhari, Hamdan Said \\ Universiti Teknologi Malaysia, Malaysia \\ *adnan_kalim@yahoo.com
}

\begin{abstract}
This paper aims to explore the need of the Pakistan public university students to be educated and trained to comprehend the significance of environmental safety. Higher education has the responsibility of nation lead, especially, in training the youth to combat with emerging challenges and issues. However, the solution for these challenges --health diseases, environmental hazards, lack of equal opportunities and others-depend on the safety of environment because of its inevitable connection with everything that exists in this world. Various efforts to preserve the environment are being taken into consideration from every corner of the higher education institutes in the developed and the developing countries alike. The initiatives in Pakistan higher education context seem less with respect to the subsequent adverse affects of the destruction of environment on the growing population of the country. This study employed open-ended one-on-one interview from five higher education academic administrators $(\mathrm{N}=5)$ of Pakistan public universities. Thematic analysis produced two themes: a). importance of youth training for environmental sustainability and, b) destruction of ozone layer with six categories. The findings showed the need to revise the curriculum and educate the youth. It was also found that there is a need of combined concerted efforts from all concerned agencies, and ministries to ensure the safety of environment.
\end{abstract}

Keywords: Education for Sustainability, youth training, environmental education, curriculum, higher education

\section{Introduction}

This paper aims to explore that why the process of youth training for environmental safety and sustainability can be carried out in the viewpoint of decision makers at Pakistan Public Universities. This section firstly sets the scene that why higher education is the prime and last place for youth learning and training. The second part of this paper reviews the literature in line with the significance of higher education for environmental sustainability and then in the context of Pakistan public universities. The third section describes the research method that has been employed to address the issue of youth training. The fourth section articulates the findings and interprets these along with the discussion. The second last and fifth part of this paper concludes with the conclusions and recommendations only base on the findings, while the references are enlisted in the end of this paper. Educational institutes are deemed as the knowledge factories in the world. Apart from imparting the knowledge to the young generation, these are the training houses. Among these institutes, higher education ones bear the fundamental responsibility to make up any deficiency taken place in the process of graduating the students, in addition to train them for future challenges (ULSF, 2009). In this way the appropriate framework that can work universally best is to make every effort to move forward for sustainable development. Under the banner of sustainable development, the focus on environment is the radical step. Having aligned with this framework, these institutes need to reshape their vision and mission so that the best approaches can be mapped to move towards sustainability (Simsek \& Louis, 1994). Researchers and scholars (e. g. Orr, 2004; UNESCO, 1997) are unanimously agreed that the only way is to make everybody aware about their relationship to the mother-land, since, in search of the survival on the planet human beings have come to realize the safety of environment with such an intensity ever before now (Cortese, 2010). Though this awareness from the platform of higher education institutes have been discharged in a number of various ways under the functions of these institutes, yet how the higher education institutes are contributing for sustainable development is to be explored (Corcoran, Calder, \& Clugston, 2002). Putting in other words, firstly it is required to investigate that which type of initiatives are being taken by the higher education institutes within the availability of all forms of resources.

\section{Literature Review}

The needs of a society change with the passage of time, as the development of science and information technology have revolutionized more or less every country. The ways to enabling the human capital to 
fulfil these needs also change with the parallel speed of the society's change. This calls for these institutes to lead in such a way that not only satisfy the present needs but to ensure the future needs("World commission on environment and development, The Brundtland Report, our common future," 1987). Discussing the purpose of the educational institutes in these contexts, it guides to maintain a balance relationship between society and these institutes. Since both are interdependent on each other, the higher education institutes in developed countries have changed their views to look into the societal needs. Thus, they are changing their ways of functions with the change in the society. Teaching and learning is one of these functions, Delors, Al-Mufti, Amagi, and Carneiro (1996) are of the view that learning makes the individual to know, to do, to be, and to live. Observing these simple verbs, they may not be perceived with such intensity in reading. But in their practical use they do require the meaningful adjustment of individuals in the society. In this way, to know implies to the knowledge seeker to know them, to do implies to do the things which create a relationship with the nature, to be implies to be as a human being, to live implies to live with harmony of the nature. Hargreaves and Fink (2006) extended this array and added another verb, to live sustainably. Of course, these verbs have other contextual implications and senses, but the discussed ones here, are in the context of this study.

At another point, the great proponent of education for sustainability, Sterling (2010, p. 32) has expressed his viewpoint that why learning for sustainable future is vital in these words, "The key to a more sustainable future is learning. A self-evident statement perhaps, but it hides an important truth: that some learning - indeed, much learning that dominates currently in educational systems - will not take us towards a more sustainable future, but rather the opposite. So 'learning for sustainable development' is a radical step and movement that seeks to help assure a more liveable, secure and harmonious society than that in prospect." It has been determined base on the above mentioned discussion that learning can bring about positive and negative change in the behaviour of an individual. However, for sustainable development, there is a need of positive lifelong learning, while the major source to exercise this learning is to incorporate sustainable curriculum. In the context of Pakistan, revising curriculum is obligatory to the concerned ministries with the collaboration of the educational institutes. Here, Environmental Protection Agency (EPA) comes to play its pivotal role in revising the curriculum. Environmental Protection Act, 1997, (Pakistan, 1997) state that, "The Federal Agency shall a) recommend environmental courses, topics, literature and books for incorporation in the curricula and syllabi of educational institution; and b) promote public education and awareness of environmental issues through mass media and other means including seminars and workshops" (p.10). However, there is a lack of collaboration between EPA and educational institutes that has indirectly been said in the form of missing environmental education in educational institutes (Arif, 2009, 21st November). This paper looks into this issue from the perspective of academic administrators of public universities. It explores that if youth should be trained to understand the importance of environmental safety then how the curriculum supports to eliminate this gap. The discussion section of this paper gives elaborate points. The following section highlights the methods to address this issue.

\section{Methodology}

The sample for this study consisted of five higher education academic administrators $(\mathrm{N}=5)$ from five selected public universities of two cities in Pakistan. The nature of the study directed to select these participants who hold the position of academic administrators, decision makers, along with the experience and education of sustainability. These two characteristics were met by choosing academic administrators base on the purposive sampling (Creswell, 2007). After identifying these potential informants, they were contacted and updated about the study. It was also discussed to them that the oneon-one audio interview will be conducted for this study. They were fully assured that their identities and the institutional ones would not be employed other than the research purposes. Upon their acceptance, the procedures of interview conduct were carried out. During the interview we explored one major question and one sub-question, related to the major one. The former focused on the area of students' learning and training for sustainable development, while, the latter discussed that how the process of changing the curriculum for sustainable learning can be executed. The questions were developed base on the following statement. "The present industrial development in the developed countries have compounded the problems of maintenance of the safe environment and causing little destruction of ozone layer". While, the questions were as below:

a) Should the youth be properly educated and trained to understand the importance of the safety of environment? 
b) Should the curriculum for sustainability be designed as a part of the general curriculum or special curriculum?

All audio recorded interviews were transcribed one by one meticulously and listened over and over again till we were sure their precision, clarity and correctness. After that these interviews were individually sent back to the respondents to further endorse the transcript. These interviews were coded and analyzed manually with respect to theme emergence (Guest, MacQueen, \& Namey, 2012). These themes and relevant categories are discussed in the following section.

\section{Results and Discussion}

The below details first describe the results base on the emergence of the themes from the collected data. This is given in table 1. After this quotes from these interviews have been quoted that are further discussed. The open-ended interviewed questions have been given together because the second question is part of the first one. The following table, table I, presents the summary of the emerged themes and the related categories.

Table 1: Summary of the emerged themes and the related categories

\begin{tabular}{l}
\hline Main themes \\
\hline Importance of environmental safety \\
Need to revise the curriculum \\
Need to take decisions \\
Need to educate youth \\
Isolation of university from the community \\
Contribution to Ozone layer (contribution to SD) \\
Criticism on the west for SD contribution \\
Shift in temperature
\end{tabular}

In describing the results of this study, the informants shared information about the significance of the environmental safety can be divided in two themes. These two themes can further be categorized in four and two relevant categories respectively for theme one and theme two. Under the first category of theme one, three respondents expressed their views in favour to revise the curriculum. In second category, one of the informants described the importance of environmental safety with the viewpoint of decision making processes. Under the third category, four informants expressed the need to train the youth for environmental safety. The last and fourth category of first theme was viewed by one respondent in the form of pointing out directly the university isolation from the society. However, considering the first three respondents' views, it is very clear that they have implicitly indicated the same thing that has been discussed in the fourth category. The second theme highlights the two major categories. In the first category, the respondents have pointed out the less contribution of developed countries towards sustainable development. The second category discussed that it is a whole shift of climate change. Respondents, in the favour to revise the curriculum expressed their views as,

"Curriculum revision is important aspect for sustainability in terms of academic activities and you know the era is very advanced era. And we have to have cutting-edge technologies. So, with that perspective the curriculum should be revised. And new courses need to be designed with the perspective of the changing era and with advanced technologies we need to have curriculum revised very frequently-Participant 2.

The participant viewed the need of revising curriculum with respect to the academic activities of the university. It can reveal the curtain from the real practices of the academic activities, which might not be aligned with the functions of the university. It can also point to further exploring the reasons of not revising the curriculum. However, the expression highlights the preparation to combat with the future challenges. This is arguably appropriate for educating the youth so that they may share the burden of the society in positive directional lead. It seems that the respondent has faced issues in the context of sustainable initiatives. So, the participant is talking about the process to achieve the desired objectives. Another respondent highlighted this need in these words.

"There is a big flaw in our curriculum. I would say it is a big flaw .........Don't you think that environment is one of the most important issues that should be taken into account so that I can make optimal improvements for my country? It would not be possible without having a proper knowledge for that participant 3". 
This respondent emphasized that curriculum should be revised and apart from linking to the above one added that it is one of the most important issues. This quote can be interpreted in the way that, there might be other factors that can influence this initiative. The quote also indicates clearly that there are other issues, which might be linked with it or might not be that is further to be explored. In case of link of other issues, exploring those might streamline the revision of curriculum more than others. Similarly, the one respondent looked at this in the perspective of decision making processes in these words.

"So, that example, I may not agree with those ozone layers. However, as far as the argument is concerned fully agreed that the decisions should be taken to protect the environment-Participant 1.

These responses link with the issues raised by Mughal, Qaisrani, Solangi, and Faiz (2011). These also explain that the disintegration of EPA and university management is still widening. On the other hand, it seems that EPA might have not realized its responsibility to communicate with the universities in order to share the burden of the youth training. The dream of sustainable development can only be realized if every individual is equipped well to know and feel the sense of ownership towards the mother-land. One respondent showed the expressions about youth training in these words,

"Well, at the basic level, may be at the master or bachelor level, because we are also going to initiate BS programs at some of the faculties. In fact, the faculty of natural sciences is going to initiate BS program in the coming autumn fall semester. And the thing is that they are going to..... At BS level it should be embedded in the course - Participant 2."

The ray of hope was seen by one of the respondent that the university $\mathrm{X}$ is going to start curriculum at BS level. The significant point is that more or less these five universities have established the department or college, especially, with the focus on environmental, earth, and engineering sciences. Despite the fact, the respondents have shown the need to revise the curriculum. Linking these results with Roorda (2001), who says that for sustainability there should be inter-disciplinary curriculum, while this approach of curriculum is on top of the series of multidisciplinary, trandsicplinary, and inter-disciplinary curriculum. It seems that these universities are still at the first stage, multidisciplinary curriculum. The dire need of curriculum revision also mars the contributions being taken by these universities. On the other hand, the developed countries are exploiting the environment at larger length than the developed or underdeveloped ones. The difference might be of a slight proportion, but the notion is that the developed countries are exploiting the environment with the advancement of the new technology, while the underdeveloped and the developing ones are in the war of survival and in this case they have to meet their basic needs which likely push them to compromise on sustainable practices. The question is left open to be explored at global level. However, in this study, the same thing has been revealed by the academic administrators, who said as,

"Obviously the technological advancement, we are the victim of their technological advancement Participant 4"

At another place the participant said,

"Pakistan is contributing very less in green house gas emissions. But Pakistan is the eighth vulnerable country in the impacts of those emissions. More than $50 \%$ of the people are totally unaware of the facts. Why are they dying? They say nature is being/ preying crazy. No. But somebody has to take the responsibility--Participant 4."

The above mentioned quote can be implied at two different levels. The first one is at the national level, and the second one is international level. Discussing the former one, it can be said base on this study that these universities have taken their initiatives by themselves. The data also shows that they have initiated to contact EPA, while EPA seems to demonstrate negligence in terms of discharging its responsibility towards sustainable development at national level. This lack of responsibility from EPA also links with this whole paper, partially, and particularly with the viewpoint of revising the curriculum from decision making processes (Participant 1). In addition to that EPA is also responsible for collaboration with the education institutes under the Environmental Protection Act (Pakistan, 1997). In this way, it proves, base on this study, that there is a lack of sustainable initiatives from EPA. The second discussion point for this quote is linked with the perspective of all the concerned agencies and ministries at international level. In simple words, the ministry of climate change and EPA should communicate and cooperate with these higher education institutes in shouldering the burden for sustainable development. Upon this, these agencies can also represent Pakistan's sustainable initiatives at any international forum. However, it seems that the current position is not as stronger as it is needed. Furthermore, it appears that the price of environmental destruction by the developed countries is being paid by the developing and under 
developed ones. This calls for to move forward with common consensus approach. In this way, it can be hoped that equality and social justice can further be reflected by every effort the countries are making.

\section{Conclusion}

Contextualizing the issue of the significance of environmental safety for youth training in Pakistan, it is linked with the functions of the public universities and their decision making processes. It is commendable that the establishment of department/ college/ institute for environment, earth, energy or with similar names, is, of course, itself a foundational sustainable initiative. The second favourable point for sustainable initiative is that all the respondents focused that youth should be trained with respect to know the significance of the environment. One of the respondents said that not only youth but the elders should be made aware with the collaboration of the ministry of Climate Change and the Government by special employment of TV channels. These results conclusively offer the possible opportunity to direct and orient the university youth cohort with the revise of curriculum so that human capital can be capitalized to solve the regional issues for contributing towards the global ones. These results are worthwhile in themselves but a stepping stone for universities primarily in terms of burdening the share of the community-the absent part in university functions. To some extent, these results can work like a bridge between other than mentioned agencies and ministries for the purpose of sustainable development, as the isolation of public universities is widening the gap between these institutes and community. One bad effect of this gap is the victimization of natural eco-system in the name of economic development. Since this paper is a part of the larger study, there is a need to explore the linking variables of sustainable development in Pakistan at the public universities. In this way, the sustainable development can also be reflected even though it is the outcome of slight efforts.

\section{References}

Arif, R. (2009). Environmental Education Editorial, 3.

Corcoran, P. B., Calder, W. \& Clugston, R. M. (2002). Introduction: Higher education for sustainable development. Higher Education Policy, 15(1), 99-103.

Cortese, A. (2010). Mobilizing higher education to create a healthy, just and sustainable society (pp. 1-13). Luther College: Second Nature: Education for sustainability.

Creswell, J. W. (2007). Qualitative Inquiry and Research Design: Choosing among five approaches Thousands Oaks, CA: Sage.

Delors, J. I., Al-Mufti, I., Amagi, I. \& Carneiro, R. (1996). Learning: The treasure within -- Report to UNESCO of the International Commission on Education for the Twenty-first Century (pp. 1-46). Paris: United Nations Educational, Scientic, and Cultural Organization.

Guest, G., MacQueen, K. L. \& Namey, E. (2012). Applied thematic analysis. Los Angeles, London, New Delhi, Singapore, Washington, DC: Sage Publications Inc.

Hargreaves, A. \& Fink, D. (2006). Sustainable Leadership. San Francisco: Jossey-Bass.

Mughal, S., Qaisrani, N., Solangi, G. \& Faiz, S. (2011). Promoting education for sustainable development: Challenges and issues for higher education institutions in Pakistan. International Journal of Learning \& Development, 1(1), 159-165.

Orr, D. (2004). Earth in mind: On education, environment and the human prospect. Washington, DC: Island Press.

Pakistan Environmental Protection Act, 1997, XXXIV C.F.R. (1997).

Roorda, N. (2001). AISHE: Auditing instrument for sustainable higher education. Dutch Committee for Sustainable Higher Education. Dutch: Dutch Committee on Sustainable Higher Education.

Simsek, H. \& Louis, K. S. (1994). Organizational change as paradigm shift - Analysis of the change process in a large, public university. Journal of Higher Education, 65(6), 670-695.

Sterling, S. (2010). What is learning for sustainable development? In M. Witthaus, K. McCandless \& R. Lambert (Eds.), Tomorrow Today (pp. 32-33). London: Tudor Rose.

ULSF. (2009). University Leaders for Sustainable Future. website, Retrieved August 21, 2006 at http://www.ulsf.org/about_staff.html.

UNESCO. (1997). Education for a Sustainable Future: A transdisciplinary vision for concerted action: United Nations Educational, Scientific and Cultural Organizations. World commission on environment and development, The Brundtland Report, our common future. (1987). Oxford, UK. 